\title{
Prácticas Culturales para el Caqui Japonés en Florida ${ }^{1}$
}

\author{
Ali Sarkhosh, Dustin M. Huff y Peter C. Andersen²
}

\section{Zonas de producción}

Los caquis son considerados como un cultivo relativamente sostenible en Florida, con una calificación de 6 puntos en una escala de 10 para la evaluación de sostenibilidad agrícola. Los caquis tienen un potencial comercial moderado y altas probabilidades de llegar directamente al consumidor. La demanda de los consumidores podría ser de cultivares no astringentes principalmente. Los caquis son aptos para el centro y el norte de Florida, ya que la calidad y los rendimientos pueden ser bajos en la parte sur del estado. Los caquis tienen un bajo requisito de horas frío, y pueden producirse con éxito en áreas que reciben sólo 100-200 horas con temperaturas por debajo de $45^{\circ} \mathrm{F}\left(7^{\circ} \mathrm{C}\right)$. Los datos muestran que las yemas pueden salir de dormancia cuando las temperaturas están justo por encima del rango normas de las horas con más frio, entre $32-45^{\circ} \mathrm{F}\left(0-7^{\circ} \mathrm{C}\right)$.

De acuerdo a los datos recogidos a nivel de condado en el 2017 a nivel de condados, está claro que hay dos regiones principales de producción de caqui en Florida. Una región se encuentra en los condados contiguos de Alachua, Levy, Marion y Lake, que representan casi el 50\% de la superficie total que se cultivan en el estado (132 de 266 acres). La otra región se encuentra al norte del estado, en los condados de Okaloosa, Walton y Washington, que suman alrededor del $18 \%$ de la superficie producida. Existen algunos otros condados dispersos que tienen más de 5 acres del cultivo del caqui: Brevard (16 acres), Hernando (8 acres), y Jefferson (8 acres).

Los árboles crecen y fructifican mejor en el centro y norte de Florida. Además, pueden producir altos rendimientos con fruta de buena calidad en esas zonas. En el sur de Florida, la calidad de la fruta de cultivares astringentes es mejor que la de cultivares no astringentes. El caqui japonés no está incluido en la lista de malezas nocivas del Departamento de Agricultura de la Florida in los Estados Unidos (USDA) o en la lista de Especies de Plantas Invasivas del Consejo de Plagas Vegetales Exóticas de Florida. Para obtener información sobre los cultivares que se pueden producir en Florida, visite la publicación EDIS titulada Cultivares de Caqui Japonés en Florida, disponible en el siguiente enlace: https://edis.ifas.ufl.edu/mg460.

1. Este documento, HS1389s, es uno de una serie del Departamento de Ciencias Hortícolas, UF/IFAS Extension de la Universidad de Florida. Fecha de publicación original: diciembre 2020. Visite el sitio web de EDIS en https://edis.ifas.ufl.edu para obtener la versión actualizada de esta publicación.

2. Ali Sarkhosh, profesor asistente y especialista en Extensión, Departamento de Ciencias Hortícolas; Dustin Huff, científico biológo, Departamento de Ciencias Hortícolas; y Peter C. Andersen, profesor emérito, Departamento de Ciencias Hortícolas, Centro de Investigación y Educación del Norte de Florida en Quincy; Servicio de Extensión UF/IFAS, Gainesville, FL 32611. Traducción por Jonathan Clavijo-Herrera, estudiante de doctorado, Departamento de Ciencias Hortícolas.

El uso de nombres comerciales citados en esta publicación es sólo con el propósito de brindar información específica. El Instituto (UF/IFAS) no garantiza los productos nombrados, y las referencias a ellos en esta publicación no significa nuestra aprobación a la exclusión de otros productos de composición comparable.

Use pesticidas de manera segura. Lea y siga las instrucciones de la etiqueta del producto.

The Institute of Food and Agricultural Sciences (IFAS) is an Equal Opportunity Institution authorized to provide research, educational information and other services

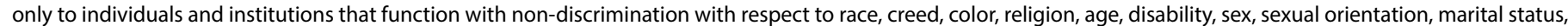

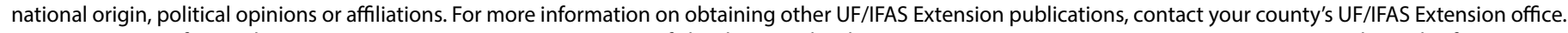
U.S. Department of Agriculture, UF/IFAS Extension Service, University of Florida, IFAS, Florida A \& M University Cooperative Extension Program, and Boards of County Commissioners Cooperating. Nick T. Place, dean for UF/IFAS Extension. 


\section{Propagación}

\section{Selección de portainjertos}

Los caquis japoneses en Florida han sido injertados casi exclusivamente con Diospyros virginiana, un caqui nativo de los Estados Unidos. D. virginiana es ampliamente utilizado en los estados del sur debido a su adaptabilidad a diferentes tipos de suelo. Dicho cultivar tiene tolerancia a suelos húmedos, es resistente al frío, puede soportar condiciones de sequía, y es compatible con la mayoría de cultivares injertados. Tiende a producir más chupones en comparación con otros portainjertos utilizados comúnmente en California, como D. lotus y D. kaki, y también pueden carecer de uniformidad y vigor. Algunas investigaciones realizadas en Florida en la década de 1960, se ha comparado el $D$. kaki y D. virginiana, encontrandose poca diferencia entre portainjertos con respecto al rendimiento. Sin embargo, se confirmó que la especie nativa de caqui promovió mayor desarrollo de chupones. D. lotus ha demostrado cierta incompatibilidad con las principales variedades no astringentes, incluyendo 'Fuyu', 'Jiro', e 'Izu'. Además, dicha especie puede producir una cantidad de fruta caída mayor en el cultivar astringente 'Hachiya'. Investigaciones recientes bastante prometedores en Japón sobre portainjertos enanos, particularmente de SH11, MKR1 y FDR-1, encontraron una alta eficiencia de rendimiento y también potencial de reducir el requerimiento de mano de obra por árbol. También, se ha demostrado que la caída de fruta es inhibida, en algunos casos, por estos cultivares enanos. Futuros ensayos en Florida, usando diferentes combinaciones de injerto-portainjerto, ayudarán a encontrar beneficios potenciales que algunos cultivares novedosos de portainjertos pueden proporcionar.

\section{Porqué se injertan los caquis}

Los portainjertos en general tienen beneficios e inconvenientes. Su idoneidad para ciertas condiciones de suelo y clima pueden variar, y deben ser seleccionados de acuerdo con esos factores. Los caquis se injertan debido a la considerablemente baja tasa de éxito con la propagación por esquejes, principalmente obtenidos de madera dura. En investigaciones donde se ha comparado plantas de caqui micropropagadas y enraizadas, con plantas injertadas, se encontró que los esquejes obtenidos de madera blanda proveniente de plantas micropropagadas tenían un porcentaje de enraizamiento promedio notablemente más alto, $22 \%$ contra un $9 \%$, cuando ambos grupos se trataron con 3000 ppm de IBA (ácido indolbutírico). La mayor tasa de enraizamiento exitoso se encontró en los esquejes obtenidos de chupones de raíz de madera blanda, proveniente de árboles micropropagados, que se desarrollaron al ser cortado el tallo del árbol. También se observó que los esquejes cortos obtenidos de chupones de raíz (3-4 cm; 1.2-1.6 pulgadas) exhibieron una tasa de enraizamiento más alta en comparación con esquejes más largos ( $25 \mathrm{~cm}$; 10 pulgadas), $70 \%$ comparado con $30 \%$ respectivamente. Se sabe que la micropropagación mejora la velocidad de enraizamiento de los esquejes debido a su efecto rejuvenecedor. Se consideraba que los chupones de raíz tenían mejor tasa de enraizamiento en comparación con los brotes debido a que los chupones de raíz son más juveniles en términos fisiológicos. Sin embargo, debido a que los árboles enraizados pueden ser más vigorosos que los árboles injertados, la propagación comercial por esquejes puede limitarse a aumentar los portainjertos, particularmente a conseguir portainjertos enanos cuando se desean árboles más pequeños en el huerto. Los árboles injertados directamente sobre plantas micropropagadas podrían exhibir rasgos negativos, como una fructificación tardía. Por lo tanto, la investigación adicional sobre el rendimiento de los portainjertos está justificada.

\section{Propagación de plántulas de portainjertos}

Los frutos de la especie local $D$. virginiana pueden ser cosechados en el otoño, que es la época en la que maduran. Las semillas se pueden remover y enjuagar en agua para eliminar la pulpa. Una vez limpias, las semillas se pueden plantarse directamente en macetas con sustrato, siempre y cuando se puedan mantener condiciones cálidas. Otra opción es aplicar fungicida a las semillas húmedas y luego almacenarlas en bolsas de plástico en un refrigerador entre $35 \mathrm{y} 45^{\circ} \mathrm{F}$ hasta la siembra. Es importante que las semillas permanezcan ligeramente húmedas para mantener la viabilidad. Semillas y plántulas de $D$. virginiana también se pueden obtener de viveros locales y disponibles en internet.

Las semillas pueden germinarse colocándolas inicialmente en papel de germinación húmedo, o periódico, antes de plantarlas en el sustrato. También pueden germinarse en camas para semillas (semilleros) dentro de un invernadero, alrededor de enero o febrero. Las plántulas más jóvenes son susceptibles a quemaduras en sus hojas debido al sol, por lo que se recomienda el uso parcial de sombra desde el principio. Las plántulas se cultivan durante el resto del año y estarán listas para recibir injertos el siguiente invierno.

Esquejes o yemas para injertos de primavera deben ser recogidos cuando están en dormancia, antes de que el tamaño de las yemas comience a incrementar, lo que en el norte de Florida ocurre generalmente antes de mediados de marzo. El material para injerto puede ser almacenado en bolsas de polietileno a $40^{\circ} \mathrm{F}\left(4.4^{\circ} \mathrm{C}\right)$ durante varias semanas, 
o incluso durante meses a $32^{\circ} \mathrm{F}\left(0^{\circ} \mathrm{C}\right)$. Sin embargo, el material debe ser revisado regularmente para asegurarse que los esquejes estén lo suficientemente húmedos con el fin de evitar la deshidratación.

\section{Métodos de injerto}

Los dos métodos más comunes para unir el injerto y portainjerto en caquis son: el injerto inglés o de lengüeta y el injerto de yema o astilla. El injerto de lengüeta se puede realizar con más efectividad durante la época de dormancia. El material para injerto con dos yemas proporciona buenos resultados, el punto de unión del injerto se envuelve con cinta o bandas de goma. El injerto se puede cubrir con una bolsa de plástico para mantener una humedad alta durante la formación de callo. Encerar el extremo cortado del injerto también puede aumentar la tasa de éxito.

El injerto de yema o astilla (Figura 1) es quizá el método de propagación más sencillo. En esta técnica, la yema o astilla se puede insertar en el portainjerto una a seis pulgadas por encima de la línea del suelo. En caquis, el momento ideal para el injerto primaveral de yemas ocurre cuando el portainjerto comienza a crecer y además puede sostener su crecimiento durante un mes o más, después del desarrollo de hojas. El injerto otoñal de yemas también es posible, si se realiza en seis o más semanas antes de la primera helada; esto para dar tiempo a la planta de completar el proceso de formación del callo. En este último caso, el brote es forzado en la primavera al año siguiente. Algo importante al forzar es cortar gradualmente el portainjerto hasta el punto de unión del injerto y no completamente, hasta que la yema comience a crecer. Es importante cubrir la astilla y la yema con cinta para injertos, lo que evita la deshidratación del tejido. Tutorear brotes nuevos evitará que estos se quiebren por el viento.

Otros métodos de propagación en caquis son utilizados en menor medida o son menos exitosos. El injerto de escudete o en " $T$ ” es una opción, pero los resultados son variables. El injerto de hendidura (Figura 2) puede ser una manera de cambiar el cultivar producido en un huerto, pero generalmente se realiza en árboles bastante viejos. Si los portainjertos están disponibles, pero los esquejes son limitados, una solución temporal sería permitir el establecimiento del portainjerto en el campo, y realizar el injerto in situ una vez que el material requerido esté disponible.

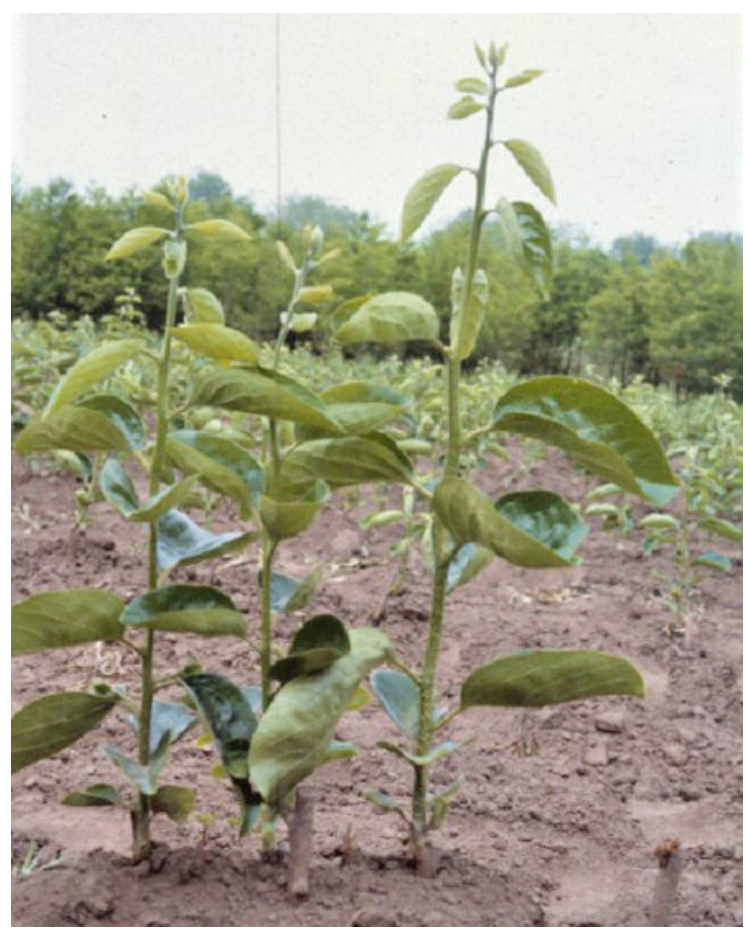

Figura 1. Árboles injertados mediante injerto de yema o astilla. Créditos: UF/IFAS

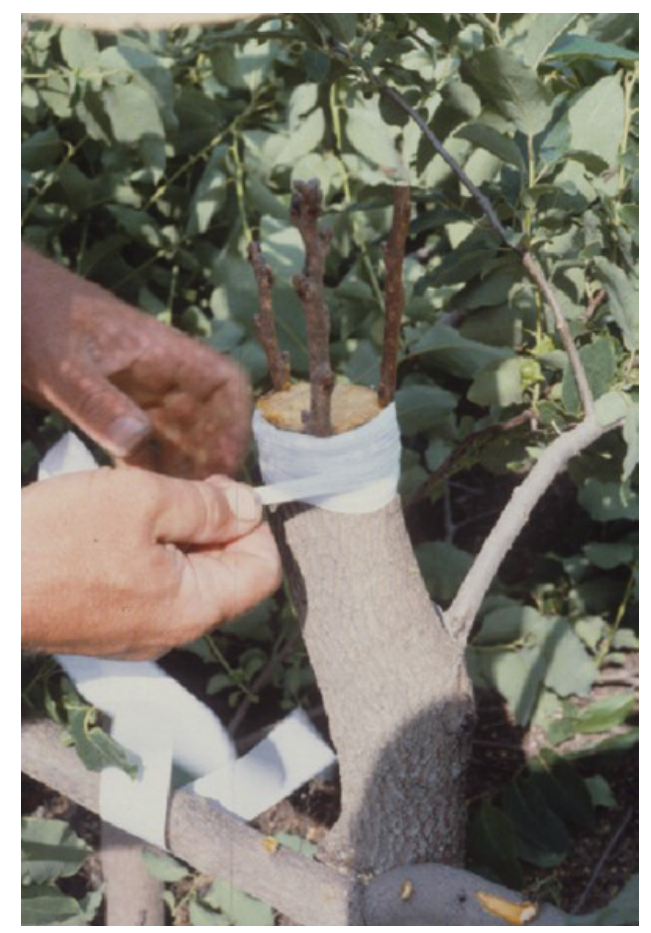

Figura 2. Árboles injertados mediante injerto de escudete. Créditos: UF/IFAS

\section{Establecimiento en campo Selección del sitio}

El mejor sitio para plantar árboles de caqui son los suelos franco-arenosos en mesetas. Se recomienda evitar áreas o "bolsones" bajos, para prevenir daños por heladas primaverales tardías que pueden ocurrir una vez que los árboles han comenzado a crecer. Los caquis se desempeñan 
mejor con un $\mathrm{pH}$ de suelo entre 6 y 7 , y son sensibles a salinidad. La madera del caqui se considera fuerte, aunque los brotes jóvenes y las ramas cargadas con frutos pueden ser sensibles al daño por viento. En lugares abiertos, establecer cortavientos podría ser necesario para disminuir ese problema.

\section{Espaciamiento}

El sistema de entrenamiento más común utilizado en caquis es el líder central modificado, que en la mayoría de áreas (con los portainjertos actuales) se puede establecer con 15 pies $(4.5 \mathrm{~m})$ entre árboles, y 20 pies $(6 \mathrm{~m})$ entre filas, lo que permite tener 145 árboles por acre. En los suelos que tienen una fertilidad natural mayor o menor, el espaciamiento se puede adaptar con base en esto, según sea necesario.

\section{Plantación inicial}

Los árboles de raíces desnudas deben trasplantarse entre diciembre y febrero. Esto se hace cavando un agujero más grande que el sistema radicular, manteniendo la unión del injerto y portainjerto en o por encima de la línea de suelo y rellenando el agujero con suelo alrededor de las raíces hasta llenarlo por completo. Los árboles en maceta se pueden trasplantar en cualquier época del año. Sin embargo, si el sistema radicular forma una esfera, es mejor plantarlos cuando están en dormancia. De manera que el suelo acumulado se puede sacudir de las raíces, las raíces podadas se pueden extender en el agujero si es necesario, evitando así la sobrecarga en el árbol durante la temporada de crecimiento. Después de plantar los árboles, es importante regarlos con un galón de agua o más, dependiendo del tamaño. Se recomienda mantener un área libre de malezas alrededor del árbol, ya sea utilizando herbicida, limpieza mecánica poco profunda o poniendo coberturas o mantillo (mulch).

\section{Riego}

Proporcionar a los árboles recién trasplantados agua en cantidad adecuada es fundamental para el establecimiento, especialmente en plantaciones de raíz desnuda, ya que el estrés debido al trasplante puede ser un gran problema en caquis jóvenes. Se requiere riego frecuente ( 2 a 4 veces por semana) después del trasplante. La cantidad de agua proporcionada se determina considerando varios factores, incluyendo la lluvia, tipo de suelo, y los niveles de evapotranspiración. El uso de microaspersores y el riego por goteo son medios efectivos para suministrar agua, $y$ también pueden ser utilizados para fertiirrigación.
A medida que un árbol de caqui madura, se volverá más tolerante a condiciones ocasionales de sequía, especialmente el portainjerto $D$. virginiana. Sin embargo, aún es esencial que el agua esté disponible para los árboles durante su fase de crecimiento, que ocurre en los primeros meses de la temporada. El riego excesivo estimula el crecimiento vegetativo exagerado durante la fase de floración y fructificación, lo que puede producirse un aumento en la caída de frutos. Investigaciones recientes sobre el uso de la aplicación de déficit regulado de irrigación (DRI) han demostrado el efecto contrario, reduciendo la caída de frutos cuando dicho déficit es aplicado a principios de la temporada. Sin embargo, esto puede generar frutos más pequeños para el tiempo de cosecha. Cuando el DRI fue aplicado más tarde en la temporada, el color en la fruta se desarrolló antes. Aún queda mucho por descubrir sobre el uso del riego y su influencia en los hábitos de fructificación del caqui.

\section{Fertilización}

Entre los años 80 y 90, se establecieron parcelas de caqui demostrativas o de investigación a pequeña escala en Florida, en 5 o más lugares. Sin embargo, estos ensayos siguieron principalmente pautas comunes para árboles frutales respecto a fertilización, por lo que hay actualmente información específica sobre los requerimientos nutricionales y tiempos para caquis en Florida.

En la Tabla 1, se muestra una recomendación general basada en el manejo dado de caquis en Florida y en las prácticas de producción comunes en Japón. Es importante tener en cuenta que se recomienda un plan de fertilización dividido, con 3 aplicaciones: un 50\% aplicado durante la dormancia tardía (marzo) y un $25 \%$ cada mes en junio y septiembre. Se sugiere aplicar un fertilizante balanceado que incluya macro y micronutrientes. La cantidad utilizada en el décimo año se puede aplicar en los años siguientes. La deficiencia de magnesio puede ocurrir si los niveles de potasio o calcio del suelo son demasiado altos. De manera similar, el manganeso y el hierro pueden ser escasos en suelos con un $\mathrm{pH}$ superior a 7. Se deben evitar las aplicaciones fuertes de nitrógeno de liberación rápida, ya que esto puede aumentar la caída de frutos.

El monitoreo de los niveles de nutrientes en las hojas es también una gran estrategia para regular un programa de fertilización. Los niveles en la Tabla 2 indican los rangos de nutrientes para los árboles de caqui de alto rendimiento en Japón. Un muestreo alrededor de la época del cuajado del fruto, y nuevamente dos meses antes de la cosecha permitiría corregir deficiencias a tiempo. 


\section{Entrenamiento y poda}

\section{Líder central modificado}

Este es el sistema de entrenamiento más común utilizado actualmente y se acerca bastante a la forma natural del árbol. En este método de entrenamiento, un árbol en dormancia recientemente plantado se corta a una altura aproximada de dos pies y medio sobre el suelo, quedando usualmente un solo tallo. En la segunda poda de invierno, el líder principal y central, que creció después de la primera poda, es recortado en $1 / 3$. Para esta etapa, habrá algunas ramificaciones laterales. Seleccione uno de los laterales con un amplio ángulo entre el tronco y la rama, creciendo aproximadamente a la altura de la marca de dos pies y medio, similar a la primera rama principal. Espaciadores de ramas también pueden ser utilizados para ampliar los ángulos entre ramas. Si es posible, seleccione otra de rama 8-12 pulgadas arriba de la primera rama, que apunte a otra dirección y quite las ramas en el tronco entre la primera y segunda rama. Durante las podas de invierno subsecuentes, el proceso de recortar $1 / 3$ del líder central, y la selección de laterales adicionales cada 8-12 pulgadas, se debe mantener. El objetivo es tener 4-6 ramas bien espaciadas que irradien desde el tronco. Una vez que esto se logra, el líder central es "modificado", cortándolo a la altura de la rama lateral final, lo que limitará aumentos significativos de altura en el futuro (Figura 3).

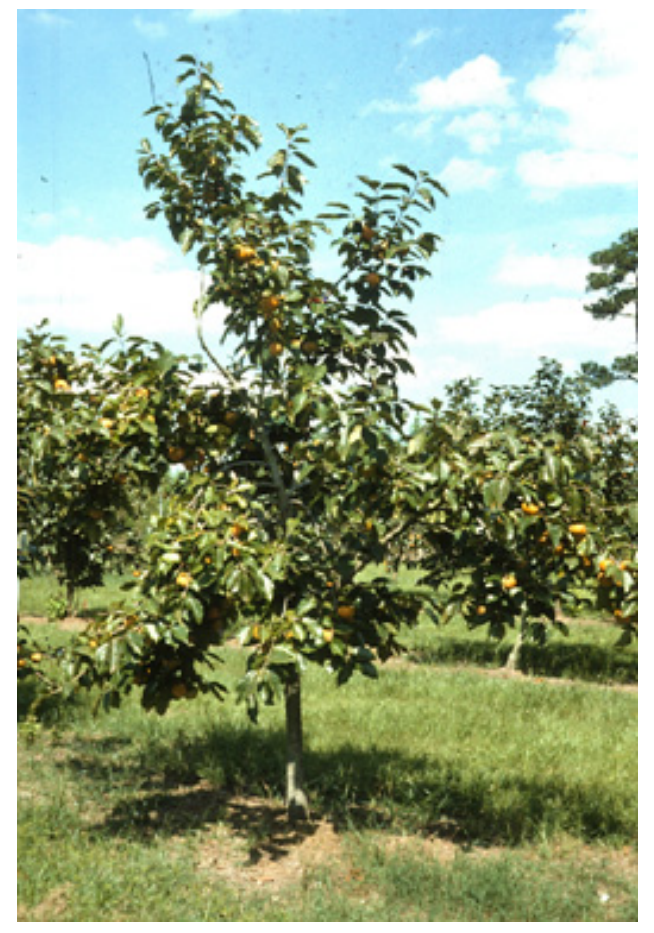

Figura 3. Sistema de líder central modificado. Créditos: UF/IFAS

\section{Sistema Palmette}

Este sistema requiere el uso de un enrejado alto. Sin embargo, permite duplicar el número de árboles por acre hasta 290 árboles siguiendo un espacio de 15 pies entre árboles y de 10 pies entre filas. El número de alambres horizontales varía, pero es común usar 3 o 4 . El alambre inferior se coloca a 40 pulgadas sobre el suelo, y los alambres adicionales se añaden cada 3 pies sobre el primer alambre. Dos ramas opuestas, en línea con el enrejado y alrededor de 2 pies sobre suelo, son elegidas y se acoplan al enrejado situado en un ángulo ascendente de 45 grados. Esparcidores de ramas también se pueden utilizar en este proceso.

Elevando el tronco de crecimiento central, pares de ramas opuestas cada dos pies se acoplan al enrejado para formar el siguiente nivel de crecimiento. Visualmente, este sistema producirá una copa vertical aplanada que se asemeja a una pluma. El enrejado también puede ser usado como una estructura para la protección contra heladas, utilizando material cobertor, o redes para prevenir el daño por aves.

\section{Otros sistemas}

Existen muchos otros métodos de entrenamiento, como el centrado abierto, en forma de $\mathrm{Y}$, o variaciones en los diseños de enrejado. Investigaciones recientes sobre un sistema de entrenamiento horizontal mostraron un mayor potencial de rendimiento y una reducción de escaleras debido a la formación de una copa más baja. Técnicas de restricción de la zona radicular pueden permitir plantaciones de muy alta densidad, con más de 1500 árboles por acre, aunque todavía se desconocen las perspectivas a largo plazo. Al elegir un sistema de entrenamiento, el costo-beneficio siempre debe ser considerado.

\section{Poda general}

Una poda fuerte en caqui a menudo no es necesaria o beneficiosa. Cuando las principales ramas estructurales están en su lugar, algunas son podadas ligeramente y sus meristemas apicales removidos cada temporada, para estimular más ramificaciones, mientras que otras no se podan. El área de fructificación en el árbol se alejará del tronco con el paso de los años al usar este método, y la densidad de ramas aumentará. En algunas áreas de alta densidad, los frutos tendrán que ser raleados ocasionalmente, con el fin de asegurar que la distribución de luz dentro de la copa sea adecuada. Cualquier rama que no se ajuste al sistema de entrenamiento que se está utilizando puede ser podada o eliminada y cuanto antes se haga mejores serán los resultados. 


\section{Floración y fructificación}

\section{Floración}

Los caquis florecen y producen fruta en ramas cuyo tejido se ha desarrollado en la temporada actual, lo que ocurre varias semanas después de la apertura de yemas vegetativas. Muchas de las variedades comúnmente cultivadas producen flores femeninas (Figuras 4 y 6). Estas se desarrollan individualmente y se identifican fácilmente por el gran cáliz de cuatro lóbulos que las rodea, el cual juega un papel importante en el desarrollo de la fruta. Las flores masculinas son más pequeñas y crecen en ramos de tallos pequeños (Figura 5). Los caquis pueden producir una cantidad modesta de frutos partenocárpicos (sin fertilización). Sin embargo, incluir algunos árboles polinizadores dispersados en la plantación mejorará el rendimiento máximo. Una proporción de 1:15 (polinizador:variedad principal) se utilizó en un ensayo demostrativo en Florida y aunque esta proporción genera una cantidad excesiva de frutos cuajados, también puede ayudar a prevenir la caída excesiva de frutos, lo que permite asegurar una buena producción. Se sugiere una proporción de 1:15-1:40 para Florida. 'Gailey' y 'Nishimura' son los polinizadores más utilizados, conocidos por su abundante producción de flores masculinas (para obtener más información sobre polinización y características de diversos cultivares, visite Cultivares de Caqui Japonés en Florida en: https://edis.ifas.ufl.edu/mg460).

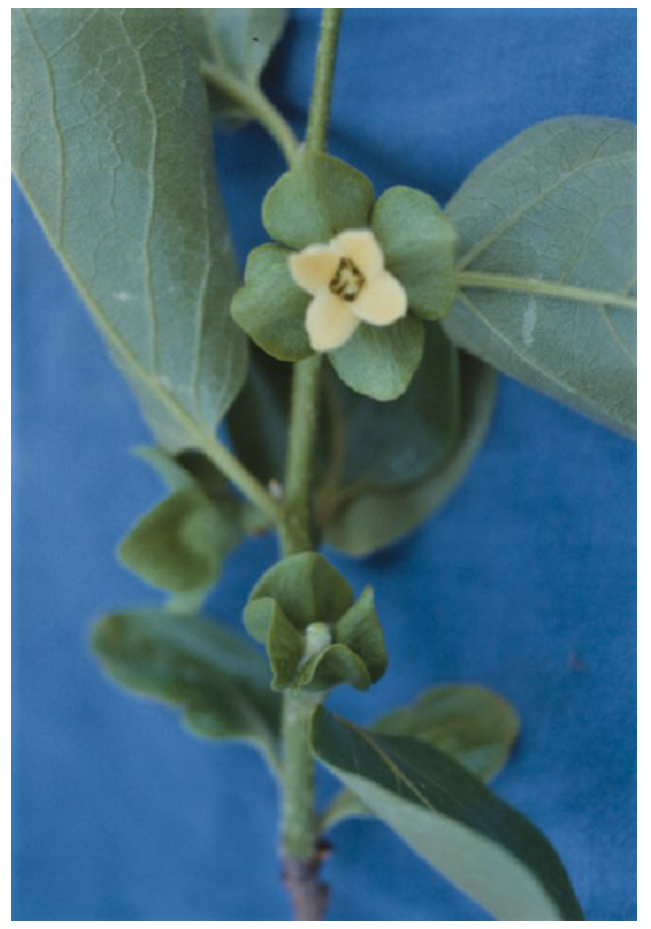

Figura 4. Flor femenina de caqui.

Créditos: UF/IFAS

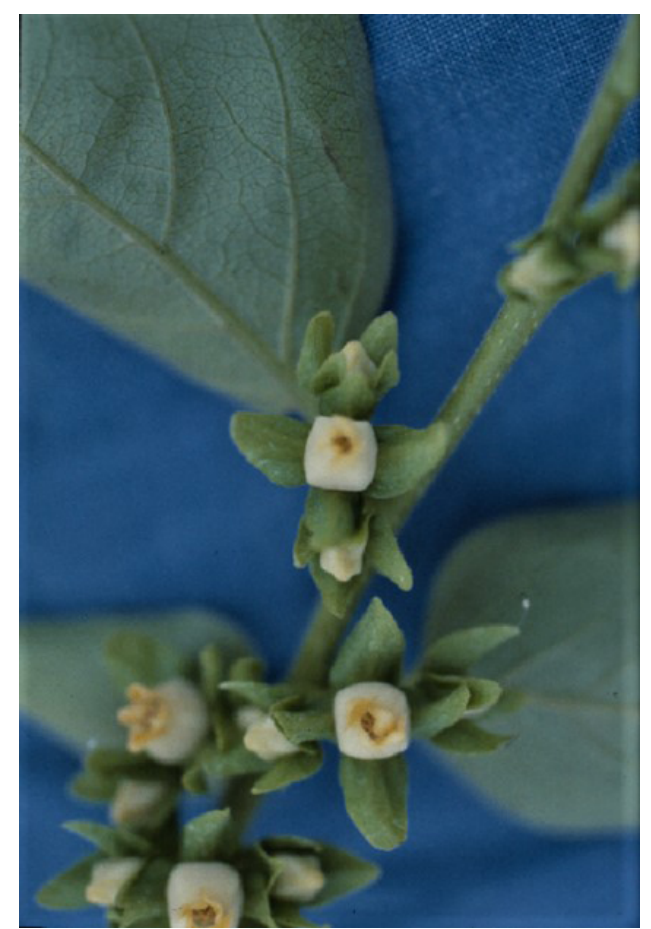

Figura 5. Flores masculinas de caqui.

Créditos: UF/IFAS

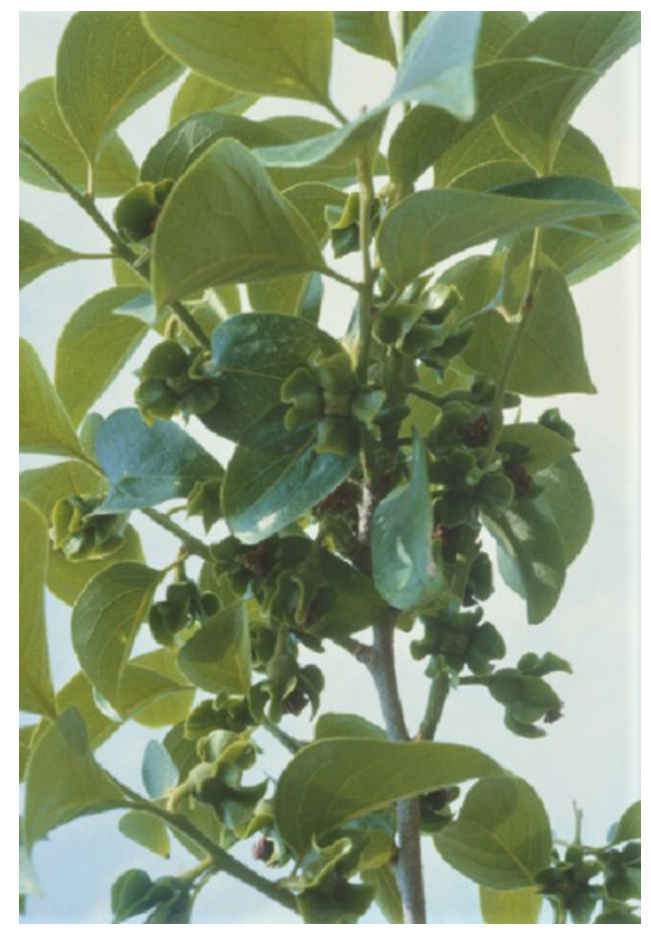

Figura 6. Brotes de caqui con flores. Créditos: UF/IFAS

\section{Fructificación}

Generalmente, una caída de frutos inicial ocurre después de la caída de pétalos. La duración de dicho período de caída depende de múltiples factores, como la cantidad de fruto producida en la temporada anterior, la polinización, el agua, los excesos de nutrientes o la falta de infiltración de luz en la copa. Caídas de fruto posteriores pueden ocurrir en junio e incluso después, pero normalmente son más 
leves. La polinización reduce la caída de frutos, pero al aumentar el número de frutos será necesario un raleo más intenso para llegar a un nivel de producción sostenible, ya que los caquis tienden a alternar su producción (alternancia entre un año de alta producción y otro de baja producción) si la carga de fruta es alta. Los árboles maduros de cultivares que producen frutos más pequeños pueden sostener 250-300 frutos por árbol en la madurez, mientras que los cultivares con frutos más grandes pueden sostener 150-200 frutos por árbol. Los árboles comienzan a producir frutos en el tercer año, y se necesitan alrededor de 8-10 años para alcanzar niveles de producción plena. Datos de producción recientes de 2013-2014 en California muestran que el rendimiento medio del caqui es de 5.4 toneladas por acre. Las estimaciones de producción en el sur de Florida son de alrededor de 3.6-5.4 toneladas por acre, y el norte de Florida están cerca del límite superior de dicho rango. Los rendimientos son generalmente más bajos para las variedades no astringentes.

\section{Raleo de frutos}

El raleo de frutos es a menudo necesario en caqui, esto para regular la carga de fruta sostenida por el árbol (Figura 7) y para ayudar a limitar la tendencia a la producción alterna. Parte de la regulación de la carga de fruta puede ser hecha mediante una poda razonable durante el invierno. La mayoría de las yemas florales crecerán a partir de las pocas yemas terminales presentes en las puntas de las ramas. Al dejar algunas de estas ramas sin podar o solamente con una o dos yemas removidas y podando además ramas débiles, la necesidad de raleo de frutos es menor. El raleo manual se realiza justo después de la primera ola de caída natural de fruta, o unas 3 semanas después de la floración. Los frutos en las ramas deben tener alrededor de 6 pulgadas de distancia entre ellos para prevenir daño por fricción entre frutos adyacentes. Descartar cualquier fruta deformada o dañada y dejar la fruta con el cáliz más grande, es importante para obtener la mejor calidad de fruto en la cosecha.

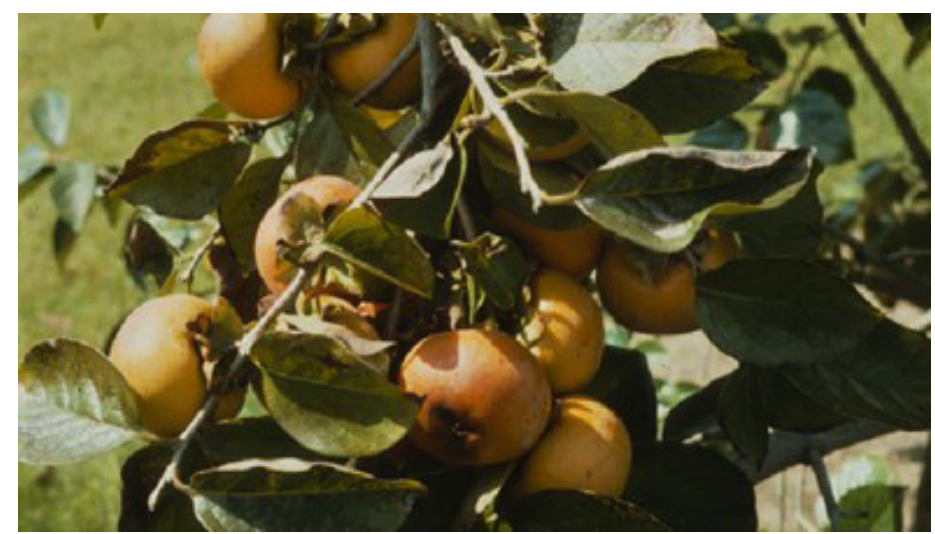

Figura 7. Carga de frutos muy pesada, sin raleo. Créditos: UF/IFAS

\section{Cosecha y postcosecha}

La temporada de maduración en caquis varía según el cultivar y se extiende de agosto a diciembre. Los cultivares no astringentes pueden ser cosechados cuando están firmes, comenzando en la fase de coloración entre amarillo y naranja hasta que alcanzan una coloración completa. Los frutos de cultivares astringentes deben cosecharse cuando llegan a coloración completa, mientras son suaves o están cerca de este punto. Cortar las frutas del árbol ayuda a evitar daños en estas, además de daños que podrían producirse en las ramas al torcer o jalar.

Los frutos de cultivares no astringentes tienden a tener una vida útil más larga en comparación con los tipos astringentes, especialmente aquellos cuya astringencia ha sido removida artificialmente. A temperatura ambiente, un cultivar no astringente como 'Fuyu' puede durar hasta 30 días. La vida útil puede prolongarse a 2 meses cuando los frutos son almacenos a $0^{\circ} \mathrm{C}$, y hasta 6 meses en condiciones de atmósfera controlada.

\section{Apertura de yemas y daño por heladas}

$\mathrm{Al}$ igual que con la mayoría de los árboles frutales cultivados en áreas donde se producen heladas a finales del invierno y principios de la primavera, los daños por frío pueden producirse en las yemas y brotes jóvenes de caqui (Figura 8). Aunque los caquis no tienen un alto requerimiento de horas frío, necesitan acumular una cantidad moderada de calor para comenzar su crecimiento. Esto retarda el desarrollo de sus hojas, en comparación con duraznos, arándanos y peras. Si el clima es cálido durante un período prolongado en enero y febrero, sin heladas, el crecimiento puede comenzar. La selección de sitios lejos de áreas bajas, el mantenimiento de niveles adecuados de nutrientes y limitar la sobreproducción de fruta, son prácticas que ayudan a reducir las posibilidades de daño por frío y mejorar la tolerancia de los árboles al estrés. Si el crecimiento de los árboles ha comenzado, el riego por aspersión (a una tasa de $1 / 4$ de pulgada por hora, para recubrir el árbol con hielo durante una noche fría y tranquila por debajo de $32^{\circ} \mathrm{F}$ ) es también una medida eficaz de protección. Si las yemas están en etapa de apertura y la temperatura es de $27^{\circ} \mathrm{F}$ por un periodo de una hora, existe riesgo de daño. El daño sufrido por yemas reproductivas debido a heladas al principio de la primavera es generalmente minimizado gracias a la apertura de yemas florales ocurrida en nuevos brotes vegetativos, después de dichos brotes haber estado creciendo durante varias semanas. 


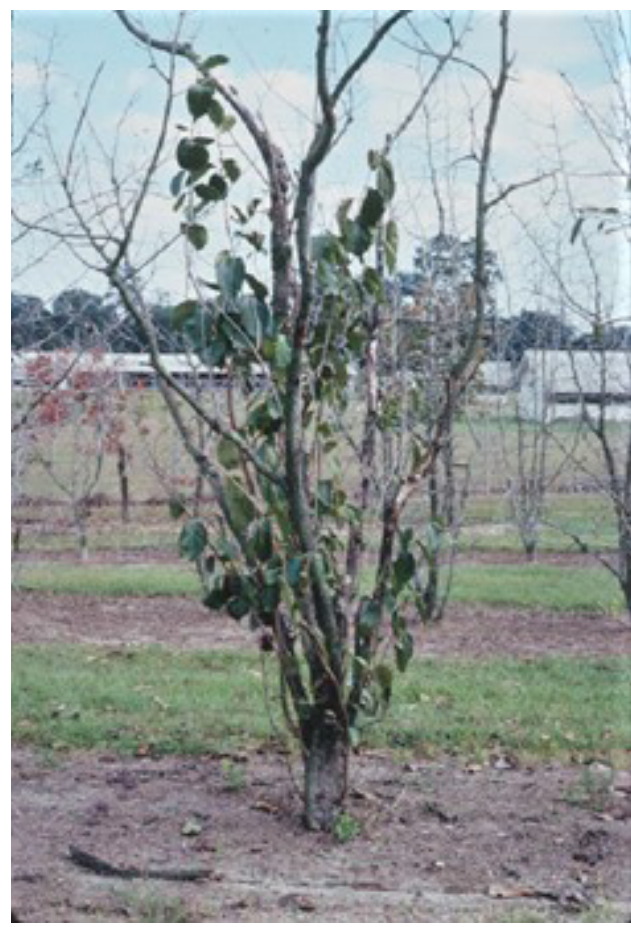

Figura 8. Daño por helada y rebrote de yemas en dormancia. Créditos: UF/IFAS

\section{Plagas y enfermedades de los caquis}

La Tabla 3 y la Tabla 4 muestran las plagas y enfermedades de caquis japoneses más comunes en Florida, sus síntomas y cómo controlarlos.

\section{Referencias}

Andersen, P. C., K. R. Athearn, A. Sarkhosh, M. A. Olmstead, and J. G. Williamson. 2020. Sustainability Assessment of Fruit and Nut Crops in North Florida and North Central Florida. HS765. Gainesville: University of Florida Institute of Food and Agricultural Sciences. https://edis.ifas.ufl.edu/ mg367

Ben-Arie, R., S. Zilkah, I. Klein, and D. Gamrasni. 2008. "Persimmon and Environment: Soil and Water Management for High Quality Fruit Production." Advances in Horticultural Science 22 (4): 286-293.

Branscome, D. 2012. White Peach Scale, Pseudaulacaspis pentagona (Targioni) (Insecta: Hemiptera: Diaspididae). EENY-076. Gainesville: University of Florida Institute of Food and Agricultural Sciences. https://edis.ifas.ufl.edu/ in 233

Crane, J. H., and C. F. Balerdi. 1997. "Estimated Crop Yields of Tropical Fruit Crops under South Florida Conditions." https://sfyl.ifas.ufl.edu/media/sfylifasufledu/miami-dade/
documents/tropical-fruit/Crop-yields-per-tree-andacre-2010.pdf

Crocker, T. E., J. G. Williamson, and J. L. Jackson. 1996. "Demonstration Plots of Alternate Fruit and Nut Crops for Central Florida." Proceedings of the Florida State Horticultural Society 109:209-211.

Davies, F. T., R. L. Geneve, D. E. Kester, and H. T. Hartmann. 2011. Hartmann and Kester's Plant Propagation: Principles and Practice. Upper Saddle River, NJ: Prentice Hall.

Frank, S., J. Baker, and S. Bambara. 2019. "Twig Girdler." NC State Extension. https://content.ces.ncsu.edu/ twig-girdler-1

George, A., B. Nissen, R. Broadley, R. Collins, P. Rigden, S. Jeffers, B. Isaacson, S. Ledger, N. Vock, and L. Chapman. 2005. Sweet Persimmon Information Kit. Agrilink, Your Growing Guide to Better Farming Guide. Agrilink Series Q105102. Brisbane, Australia: Queensland Department of Agriculture, Forestry, and Fisheries. 168.

Gomez, C., and R. F. Mizell. 2019. Green Stink Bug, Chinavia halaris (Say) (Insecta: Hemiptera: Pentatomidae). EENY-431. Gainesville: University of Florida Institute of Food and Agricultural Sciences. https://edis.ifas.ufl.edu/ in794

Intrigliolo, D. S., L. Bonet, E. Badal, C. Besada, and A. Salvador. 2012. "Regulated Deficit Irrigation of 'Rojo Brillante' Persimmon (Dyospyros kaki) Yield, Fruit Quality and Post-harvest Performance." VII International Symposium on Irrigation of Horticultural Crops 1038:415-422.

Jackson, D., N. E. Looney, and M. Morley-Bunker, eds. 2011. Temperate and Subtropical Fruit Production. CABI. 260-265.

Kim, W. S., S. J. Chung, K. Y. Kim, T. DeJong, and H. S. Choi. 2002. "Relationships between Ca, K and Mg Concentration and Browning of Blossom End Part of 'Fuyu' Sweet Persimmon during MA Storage." Advances in Horticultural Science 16 (2): 95-100.

Kitagawa, H., and P. Glucina. 1984. Persimmon Culture in New Zealand. Wellington, New Zealand: Science Information Publishing Center, DSIR. 
Lamborn, A. R. 2017. “Persimmon.” https://sfyl.ifas.ufl.edu/ media/sfylifasufledu/baker/docs/pdf/horticulture/educatorresources/Persimmon.pdf

McRitchie, J. J. 1979. Cephalosporium Wilt of Persimmon. Plant Pathology Circular No. 197. Fla. Dept. Agric. \& Consumer Serv. Division of Plant Industry.

Mead, F. W. 1966. Persimmon psylla. Entomology Circular No. 50. Florida Department of Agriculture, Division of Plant Industry.

Mizell, R. F., III and G. Brinen. 2015. Insect Management in Oriental Persimmon. ENY-803. Gainesville: University of Florida Institute of Food and Agricultural Sciences. https:// edis.ifas.ufl.edu/ig096

Mizell, R. F., III. 2018. Peachtree Borers in the Home and Commercial Peach Orchard. ENY-691. Gainesville: University of Florida Institute of Food and Agricultural Sciences. https://edis.ifas.ufl.edu/in489

Mizell, R. F., III. 2019. The Persimmon Borer Sannina uroceriformis Walker, Pest of Persimmon. ENY-835. Gainesville: University of Florida Institute of Food and Agricultural Sciences. https://edis.ifas.ufl.edu/in669

Mowat, A. D. 1993. "The Effect of Root Temperature on Bud Dormancy Release of Persimmon (Diospyros kaki L.)." IV International Symposium on Growing Temperate Zone Fruits in the Tropics and in the Subtropics 409:137-140.

Mowat, A. D., R. J. Collins, and A. P. George. 1993. "Cultivation of Persimmon (Diospyros kaki L.) under Tropical Conditions." IV International Symposium on Growing Temperate Zone Fruits in the Tropics and in the Subtropics 409:141-150.

Sharpe, R. H. 1966. "Persimmon Variety and Rootstock Observation." Proceedings of the Florida State Horticultural Society 79:374-378.

Tetsumura, T. 2001. "Production and Field Evaluation of Own-Rooted Trees of Japanese Persimmon (Diospyros kaki Thunb.)." PhD diss., Kyoto University.

Tetsumura, T., S. Ishimura, T. Takita, S. Funaki, H. Uchida, T. Hidaka, S. Haranoushiro, Y. Udatsu, M. Matsuo, C. Honsho, and H. Asakuma. 2019. "Tree Growth, Flowering, and Fruiting of 'Taishuu'Japanese Persimmon Grafted onto Dwarfing Rootstocks." The Horticulture Journal 88 (1):

$57-66$.
Tetsumura, T., R. Tao, and A. Sugiura. 2000. "Single-Node Stem Cuttings from Root Suckers to Propagate a Potentially Dwarfing Rootstock for Japanese Persimmon." HortTechnology 10 (4): 776-780.

Yakushiji, H., A. Azuma, H. Sugiura, A. Yamasaki, and Y. Koshita. 2014. "Comparison of Promising Dwarfing Rootstocks for 'Fuyu' Japanese Persimmon Trees.” XXIX International Horticultural Congress on Horticulture: Sustaining Lives, Livelihoods and Landscapes (IHC2014) 1130:469-472.

Yakushiji, H., and A. Nakatsuka. 2007. "Recent Persimmon Research in Japan." Jpn. J. Plant Sci 1 (2): 42-62.

Yamada, M. 2008. "Persimmon Propagation, Orchard Planting, Training and Pruning in Japan." Advances in Horticultural Science 22 (4): 269-273. 
Tabla 1. Tiempo de aplicación y cantidades (lb) de 10-10-10 con micronutrientes.

\begin{tabular}{|c|c|c|c|c|}
\hline Año & Marzo (dormancia) & Junio & Septiembre & Total aplicado \\
\hline 1 & 0.5 & 0.25 & 0.25 & 1 \\
\hline 2 & 0.875 & 0.4375 & 0.4375 & 1.75 \\
\hline 3 & 1.25 & 0.625 & 0.625 & 2.5 \\
\hline 4 & 1.625 & 0.8125 & 0.8125 & 3.25 \\
\hline 5 & 2 & 1 & 1 & 4 \\
\hline 6 & 2.375 & 1.1875 & 1.1875 & 4.75 \\
\hline 7 & 2.75 & 1.375 & 1.375 & 5.5 \\
\hline 8 & 3.125 & 1.5625 & 1.5625 & 6.25 \\
\hline 9 & 3.5 & 1.75 & 1.75 & 7 \\
\hline 10 & 3.875 & 1.9375 & 1.9375 & 7.75 \\
\hline
\end{tabular}

Tabla 2. Rangos de nutrientes en hojas de árboles de caqui de alto rendimiento en Japón.

\begin{tabular}{|l|c|l|}
\hline \multicolumn{1}{|c|}{ Elemento } & $\begin{array}{c}\text { Concentración en el } \\
\text { tejido foliar (\%) }\end{array}$ & \multicolumn{1}{|c|}{ Rol en el árbol } \\
\hline Nitrógeno & $2.22-3.15$ & Aumento de la producción de flores \\
\hline Fósforo & $0.11-0.16$ & Mejorar el color de la fruta, desarrollo de raíces \\
\hline Potasio & $1.47-3.86$ & Promover crecimiento de brotes, el peso de la fruta, la regulación del agua \\
\hline Calcio & $0.92-2.78$ & Prevenir deformidades en brotes, mejorar vida útil \\
\hline Magnesio & $0.22-0.77$ & Producción de semillas, transporte de fósforo \\
\hline
\end{tabular}


Tabla 3. Principales plagas de insectos de caquis japoneses en Florida.

\begin{tabular}{|c|c|c|}
\hline Plagas de insectos & Síntomas & Control \\
\hline $\begin{array}{l}\text { Escamas (Figuras } 9 \text { y } 10 \text { ) } \\
\text { principalmente escama blanca } \\
\text { del durazno (Pseudaulacaspis } \\
\text { pentagona) }\end{array}$ & $\begin{array}{l}\text { Manchas blancas, como nieve, en el tronco y } \\
\text { las ramas, fáciles de ser raspadas. Más visible } \\
\text { durante el clima cálido, cuando los machos } \\
\text { emergen. }\end{array}$ & $\begin{array}{l}\text { 3\% aceite inactivo aplicado antes de la apertura } \\
\text { de yemas, aceite de verano, o dos aplicaciones de } \\
\text { pesticidas con 1-2 semanas de diferencia (imidacloprid } \\
\text { MOA 4A, ejemplo: Provado 1.6F; sal de potasio, } \\
\text { ejemplo: Safer soap o Scalecide). Escarabajos } \\
\text { "mariquita" y crisopas para el control biológico. }\end{array}$ \\
\hline $\begin{array}{l}\text { Psílidos de caqui (Figuras } 11 \text { y12) } \\
\text { (Trioza diospyri) }\end{array}$ & $\begin{array}{l}\text { Hojas jóvenes arrugadas y deformadas, } \\
\text { crecimiento atrofiado. Ninfas de color blanco } \\
\text { que se encuentran dentro de hojas deformadas. } \\
\text { y adultos de cuerpo negro en la superficie de las } \\
\text { hojas. Cochinillas harinosas o blancas también } \\
\text { pueden estar presentes. }\end{array}$ & $\begin{array}{l}\text { Lo mejor es el control temprano, los aerosoles son } \\
\text { menos efectivos cuando las hojas se curvan. Muchas } \\
\text { opciones de pesticidas. También puede ser necesario } \\
\text { controlar las hormigas que se alimentan de la melaza. }\end{array}$ \\
\hline $\begin{array}{l}\text { Anillador de ramas (Oncideres } \\
\text { cingulata) }\end{array}$ & $\begin{array}{l}\text { Ramas anilladas presentes en los árboles o que } \\
\text { se han roto y caído al suelo con sus hojas. El } \\
\text { anillador de ramas también puede transmitir la } \\
\text { enfermedad de marchitez. }\end{array}$ & $\begin{array}{l}\text { Remover ramas anilladas para prevenir la acumulación } \\
\text { de plaga. Aplicaciones foliares preventivas en otoño } \\
\text { son mejores, cuando se depositan los huevos. } \\
\text { (Piretroides MOA 3A, ejemplo: Pyrenone Crop Spray) }\end{array}$ \\
\hline $\begin{array}{l}\text { Barrenador de árboles (Figuras } \\
13 \text { y 14) (múltiples especies, } \\
\text { incluyendo Sannina uroceriformis) }\end{array}$ & $\begin{array}{l}\text { Savia gomosa, excrementos, o aserrín que } \\
\text { proviene de pequeños agujeros en la corteza, } \\
\text { cortes de poda, o tronco cerca de la línea del } \\
\text { suelo. }\end{array}$ & $\begin{array}{l}\text { Para prevenir el ingreso de larvas, es bueno realizar } \\
\text { aplicaciones en marzo y junio. Información limitada } \\
\text { sobre el control directo, los métodos de control } \\
\text { para el barrenador de durazno pueden ser efectivos } \\
\text { (Imidacloprid). }\end{array}$ \\
\hline $\begin{array}{l}\text { Chinches hediondas (Figura 15) } \\
\text { (múltiples miembros de la familia } \\
\text { Pentatomidae) }\end{array}$ & $\begin{array}{l}\text { El daño se manifiesta como secciones } \\
\text { blanquecinas en el fruto durante el desarrollo } \\
\text { de color, y estas áreas pueden degenerarse. } \\
\text { Es un problema solamente en cultivares no } \\
\text { astringentes. }\end{array}$ & $\begin{array}{l}\text { En ciertas etapas de su ciclo de vida, estos insectos } \\
\text { pueden ser parasitados y controlados biológicamente } \\
\text { por avispas o moscas. Control químico (Piretroides } \\
\text { MOA 3A, ejemplo: Pyrenone Crop Spray) }\end{array}$ \\
\hline Trips (múltiples especies) & $\begin{array}{l}\text { La fruta puede ser afectada en el sur de Florida. } \\
\text { Son a menudo observados alrededor de la } \\
\text { época de cuaje de frutos y floración. Pueden } \\
\text { causar deformidades en la fruta. }\end{array}$ & $\begin{array}{l}\text { Aplicaciones en las hojas funcionan mejor en las } \\
\text { etapas tempranas de desarrollo del fruto. (Bonide } \\
\text { Rotenone/Pyrethrin, Pyrellin, Pyrenone Crop Spray) }\end{array}$ \\
\hline $\begin{array}{l}\text { Orugas (Malacosoma disstria) } \\
\text { Escarabajos (Phyllophaga spp.) }\end{array}$ & $\begin{array}{l}\text { Orugas y escarabajos pueden alimentarse de } \\
\text { hojas al inicio de la temporada. En otoño, más } \\
\text { adelante en la temporada, los gusanos de red } \\
\text { pueden ser un problema. }\end{array}$ & $\begin{array}{l}\text { Aplicaciones foliares en el momento adecuado en } \\
\text { primavera, y en otoño cuando sea necesario. }\end{array}$ \\
\hline
\end{tabular}

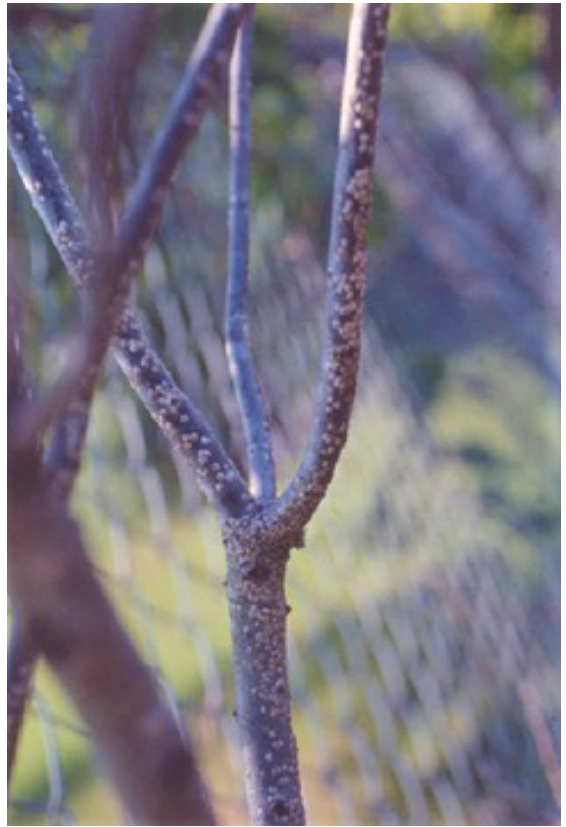

Figura 9. Escamas en caqui. Créditos: UF/IFAS

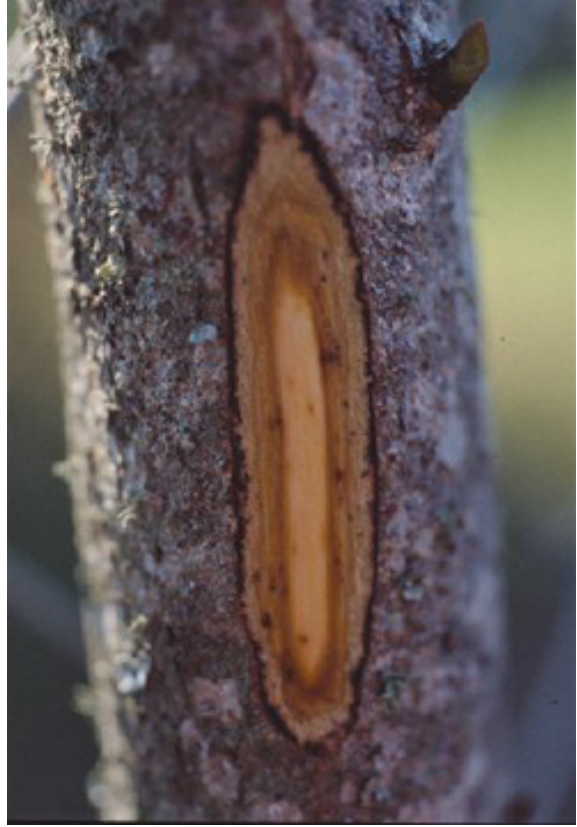

Figura 10. Daño debajo de la corteza, producido por escamas. Créditos: UF/IFAS 


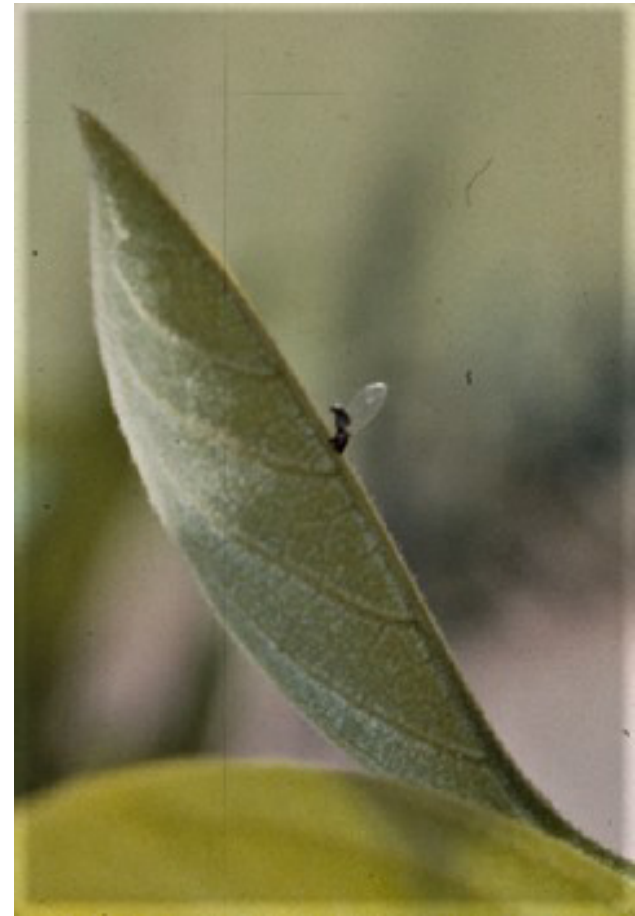

Figura 11. Psílido adulto en una hoja de caqui.

Créditos: UF/IFAS

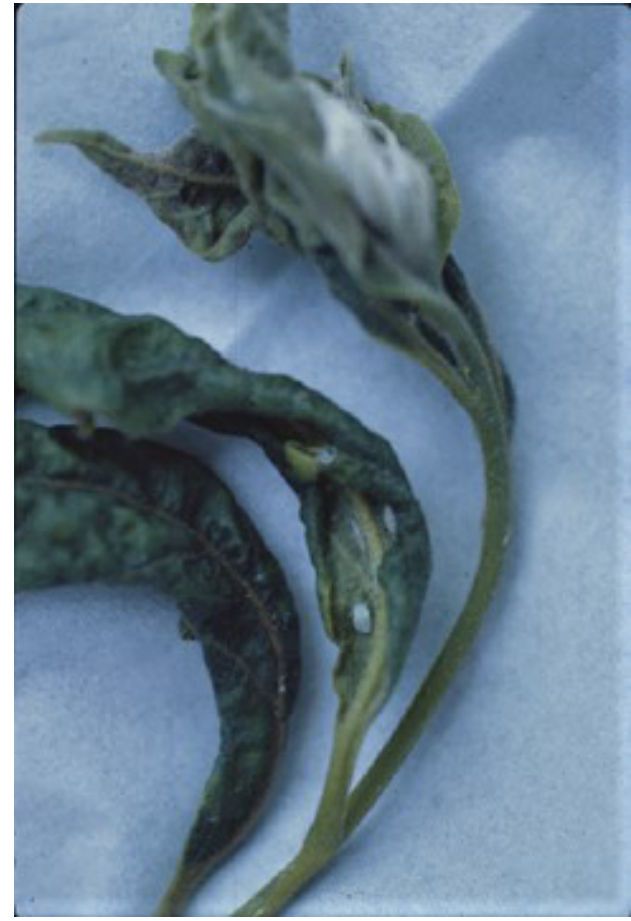

Figura 12. Ninfas de psílido en hojas deformadas. Créditos: UF/IFAS

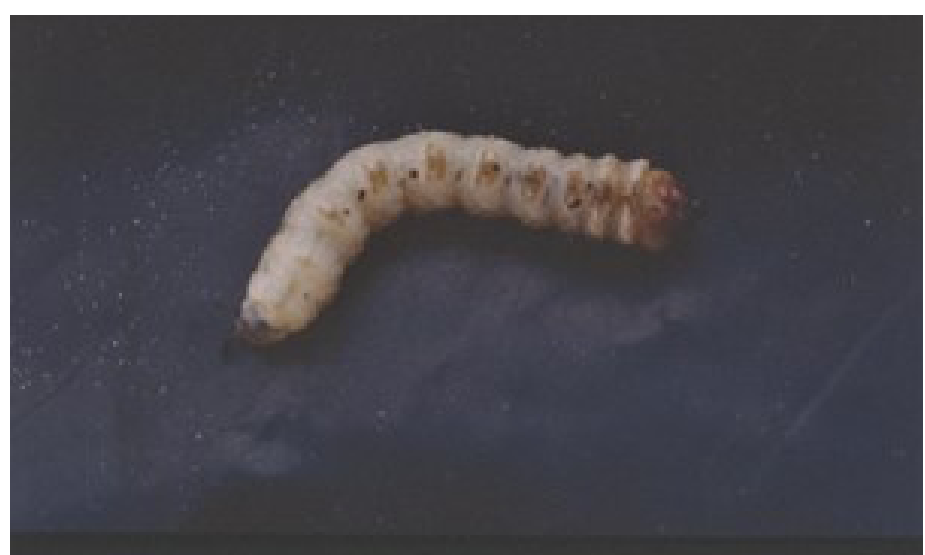

Figura 13. Barrenador de árboles de caqui. Créditos: UF/IFAS

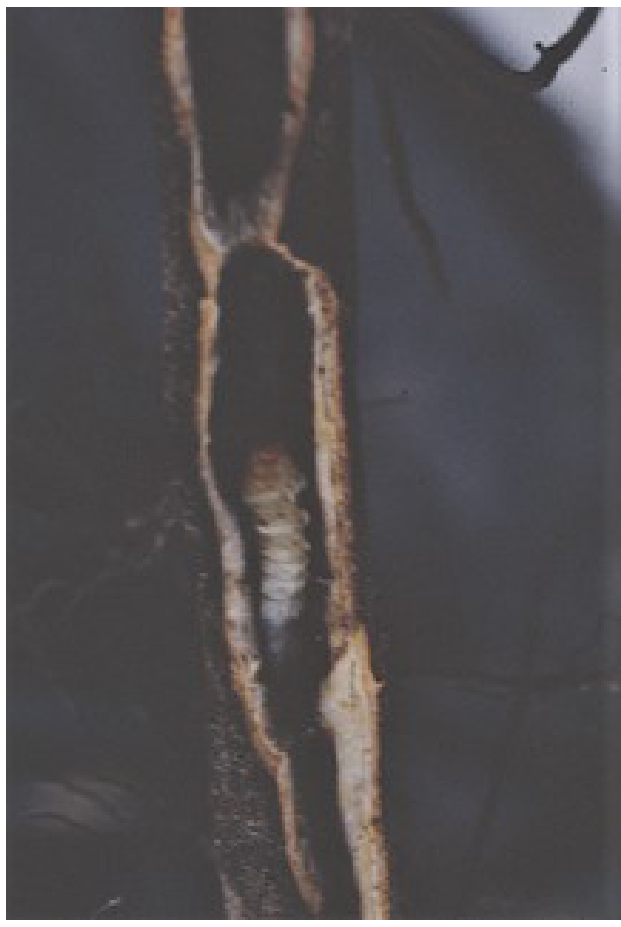

Figura 14. Barrenador dentro de la raíz Créditos: UF/IFAS

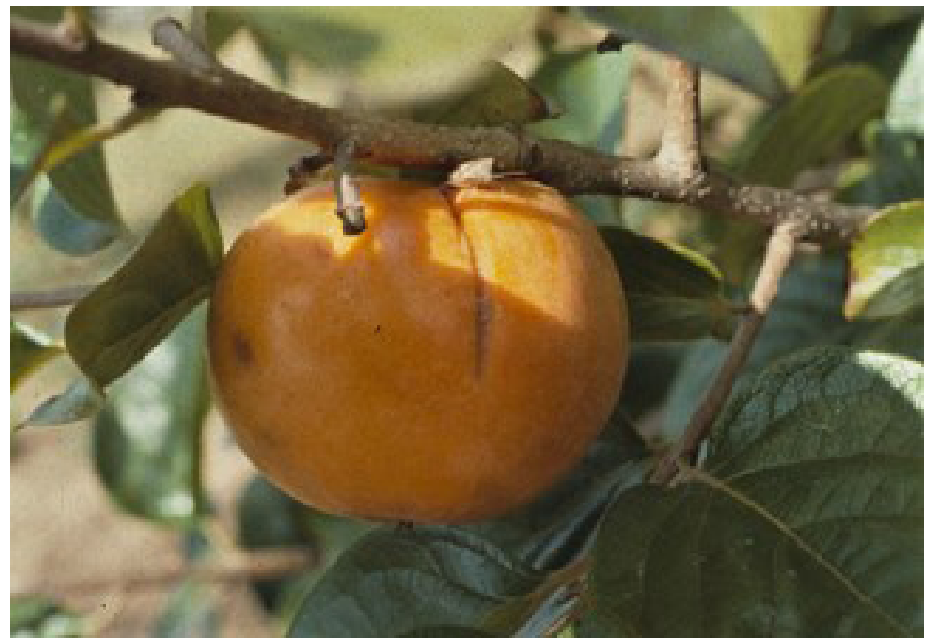

Figura 15. Chinche hedionda en el fruto del caqui. Créditos: UF/IFAS 
Tabla 4. Principales enfermedades de los caquis japoneses en Florida.

\begin{tabular}{|c|c|c|}
\hline Enfermedades & Síntomas & Control \\
\hline $\begin{array}{l}\text { Cáncer por Botryosphaeria } \\
\text { (Figura 23) (Botryosphaeria dothidea, B. } \\
\text { rhodinina, B. obtusa, y B. ribis) }\end{array}$ & $\begin{array}{l}\text { Puede haber decoloración de la madera y } \\
\text { cicatrices profundas y alargadas en la corteza. } \\
\text { Esta enfermedad es el factor limitante para el } \\
\text { cultivo de caquis en Florida, y el sur en general. } \\
\text { A menudo, este hongo limita la vida útil de los } \\
\text { caquis japoneses a entre } 8 \text { y } 12 \text { años (o incluso } \\
\text { menos). }\end{array}$ & $\begin{array}{l}\text { No hay un buen control químico. } \\
\text { Podar para aumentar el ángulo entre } \\
\text { tronco y rama, poda durante días } \\
\text { secos, desinfección de herramientas, } \\
\text { mantener un buen flujo de aire en la copa, } \\
\text { reduciendo el estrés por agua o nutrientes } \\
\text { en los árboles, y un buen programa } \\
\text { aplicación de fungicidas son las acciones } \\
\text { recomendadas para ayudar a reducir la } \\
\text { incidencia de este hongo. }\end{array}$ \\
\hline $\begin{array}{l}\text { Manchas en hojas y frutas } \\
\text { (Figuras } 16 \text { a 21) } \\
\text { (Cercospora spp., Alternaria spp., Gloeosporium } \\
\text { spp., Phyllosticta spp., Botrytis cinerea, } \\
\text { Pseudomonas syringae, Colletotrichum sp., } \\
\text { Ramularia sp.) }\end{array}$ & $\begin{array}{l}\text { Cercospora - Manchas en la hoja y defoliación } \\
\text { temprana. } \\
\text { Gloeosporium - Antracnosis o "pudrición } \\
\text { amarga", que afecta frutos y brotes. } \\
\text { Colletotrichum - Afecta a la fruta madura. } \\
\text { Ramularia - Manchas foliares a veces presentes } \\
\text { a mitad de temporada. } \\
\text { Botrytis - Manchas marrones en las hojas. } \\
\text { Pseudomonas - Manchas en hojas por "explosión } \\
\text { bacteriana", además de tallos y pecíolos } \\
\text { ennegrecidos. }\end{array}$ & $\begin{array}{l}\text { Aplicaciones foliares de fungicidas } \\
\text { preventivas a principios de temporada, } \\
\text { aplicaciones de cobertura rotando } \\
\text { productos en el verano. }\end{array}$ \\
\hline $\begin{array}{l}\text { Marchitez del caqui (Figura 22) } \\
\text { (Cephalosporium diospyri) }\end{array}$ & $\begin{array}{l}\text { El portainjerto } D \text {. virginiana es susceptible a } \\
\text { esta enfermedad. } D \text {. kaki y } D \text {. lotus son inmunes. } \\
\text { Si el injerto } D \text {. kaki tiene el patógeno, puede } \\
\text { moverse al portainjerto nativo y matar el árbol. } \\
\text { Los síntomas incluyen marchitez y muerte en la } \\
\text { copa de los árboles. }\end{array}$ & \multirow[t]{2}{*}{$\begin{array}{l}\text { Utilice material de injerto limpio durante la } \\
\text { propagación, retire las plantas infectadas } \\
\text { rápidamente y desinfecte las herramientas } \\
\text { de poda al cambiar de árbol. }\end{array}$} \\
\hline $\begin{array}{l}\text { Phomopsis spp., Verticillium albo-atrum, } \\
\text { Botryosphaeria dothidea (Figuras } 23 \text { y } 24 \text { ) }\end{array}$ & $\begin{array}{l}\text { Puede causar hojas y frutos pequeños, y } \\
\text { ramas terminales sin hojas. También puede } \\
\text { causar marchitez, decaimiento de brotes, } \\
\text { agrietamiento de la corteza en las uniones de } \\
\text { ramas. }\end{array}$ & \\
\hline
\end{tabular}




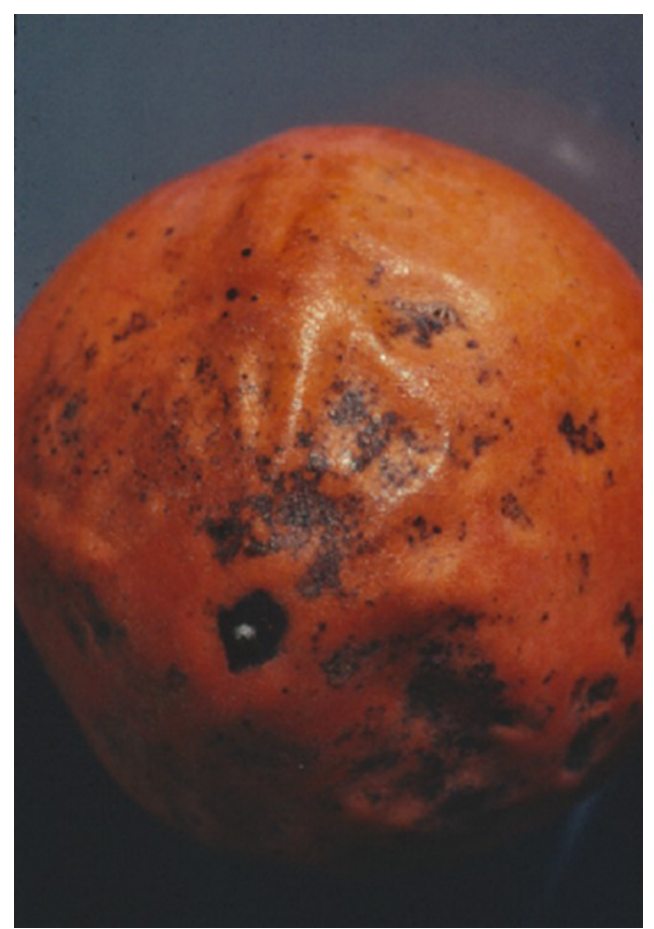

Figura 16. Mancha de la fruta de caqui.

Créditos: UF/IFAS

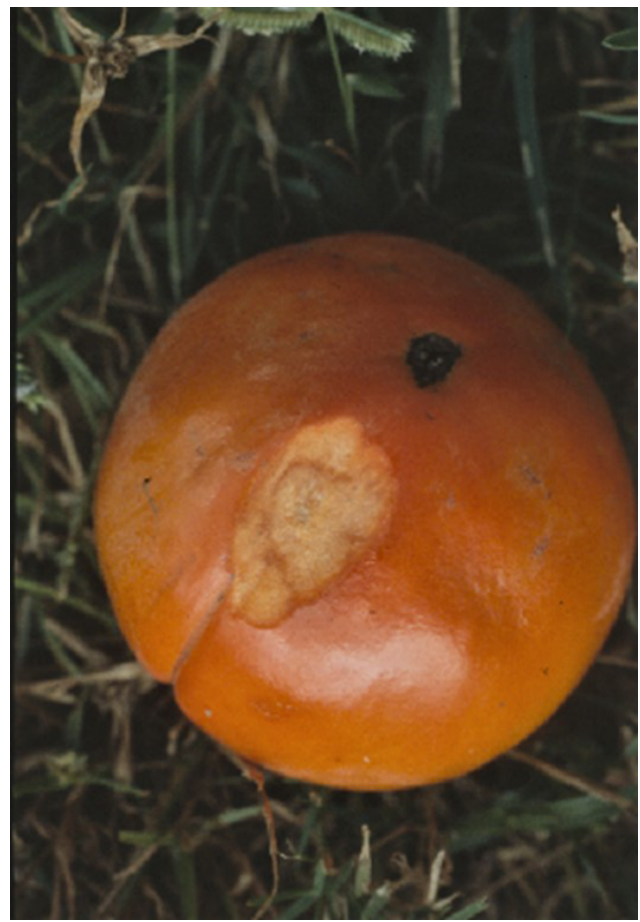

Figura 17. Antracnosis en el fruto del caqui.

Créditos: UF/IFAS

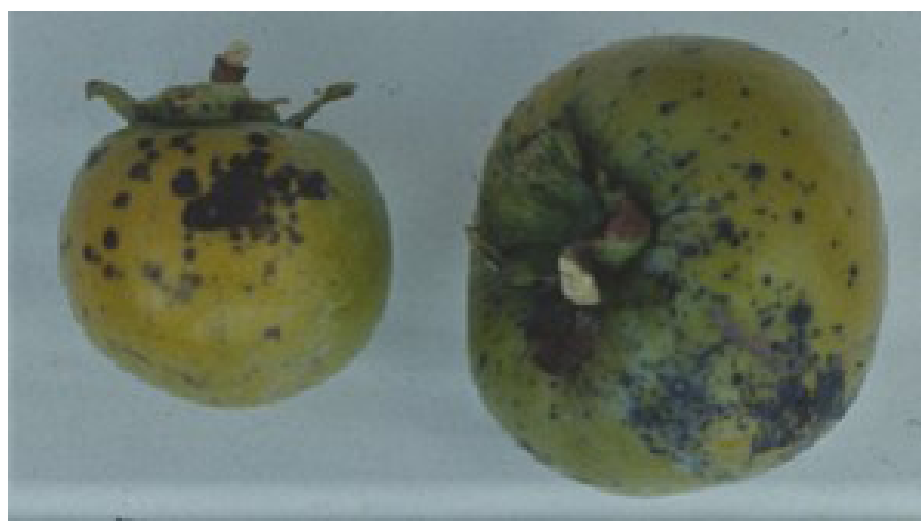

Figura 18. Antracnosis en el fruto del caqui.

Créditos: UF/IFAS

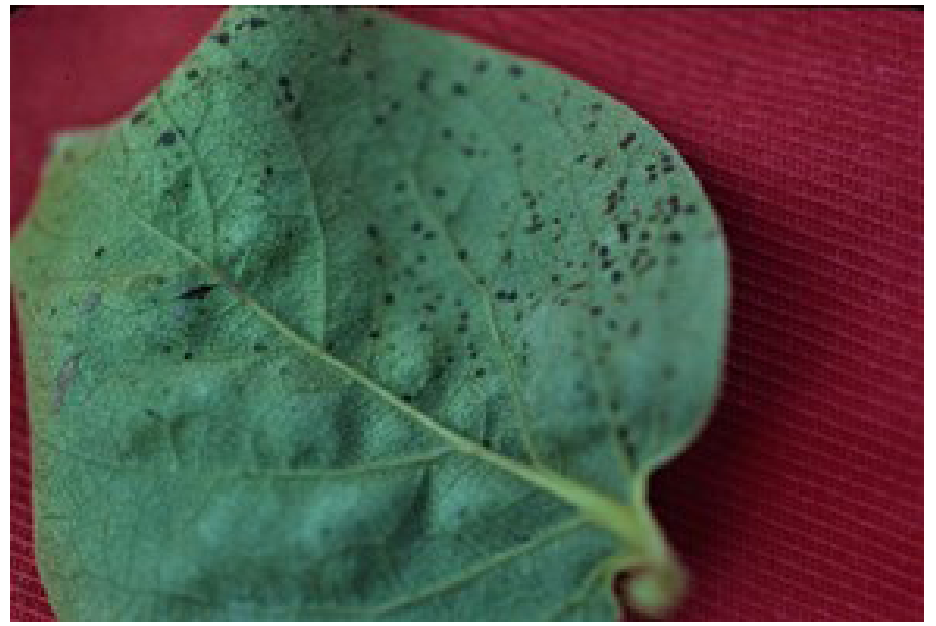

Figura 19. Mancha de la hoja de caqui.

Créditos: UF/IFAS

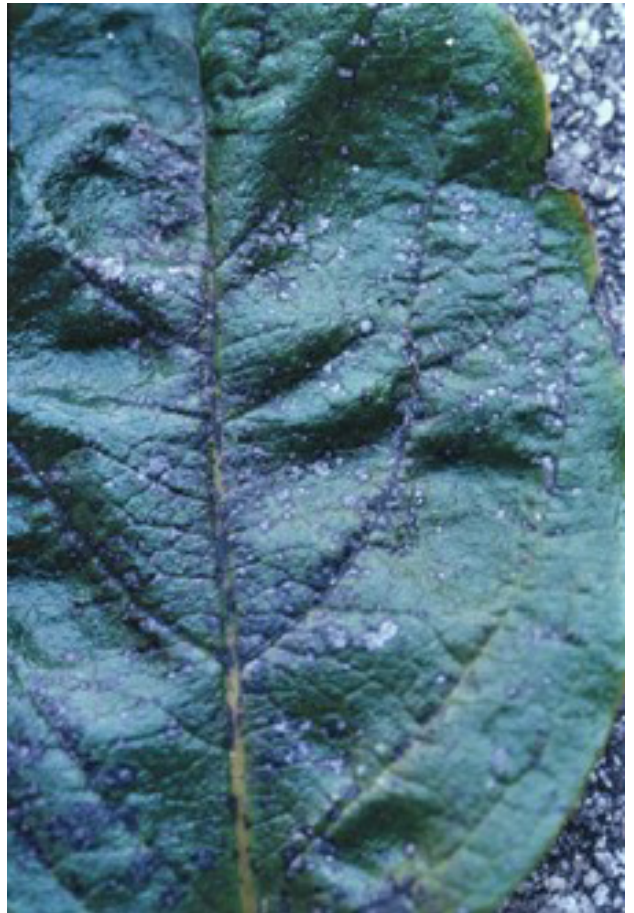

Figura 20. Mancha por Phyllosticta en hoja de caqui.

Créditos: UF/IFAS 


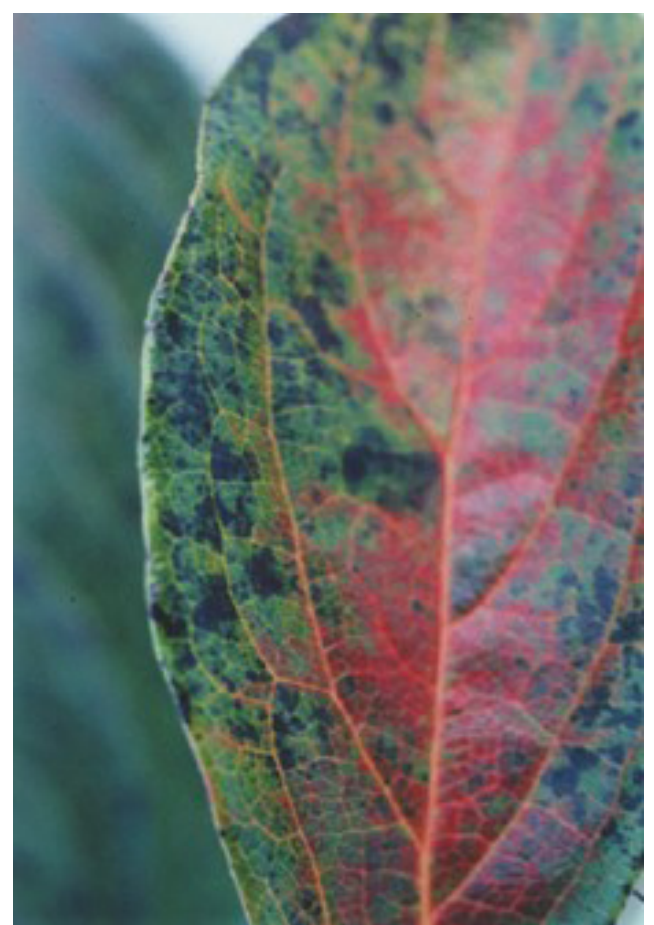

Figura 21. Mancha por Alternaria en hoja de caqui. Créditos: UF/IFAS

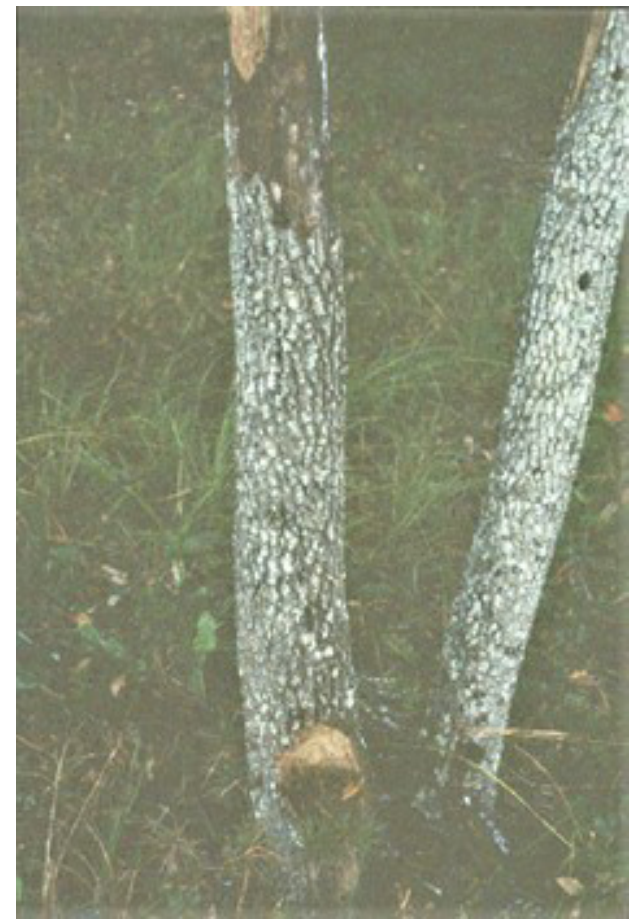

Figura 22. Daño por Cephalosporium en el tronco de caqui. Créditos: UF/IFAS

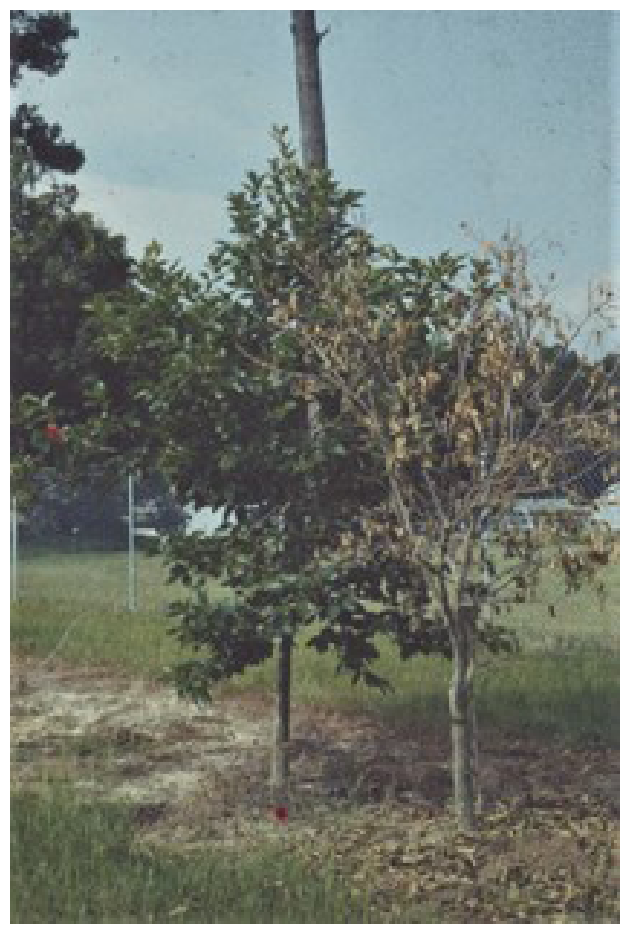

Figura 23. Decaimiento general en el árbol de caqui. Créditos: UF/IFAS

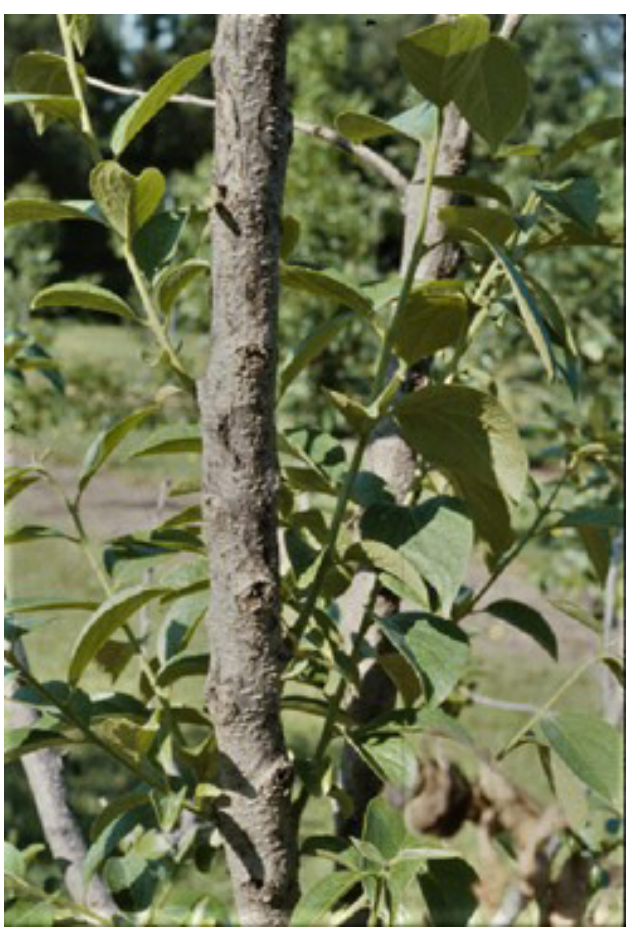

Figura 24. Decaimiento por cáncer en el tronco de caqui. Créditos: UF/IFAS 